\title{
A descriptive study of Tamil language and social identity among English-Tamils in
}

\section{Malaysia}

\begin{abstract}
This research describes the status of the Tamil language in Malaysia. More specifically, it describes the reasons of Tamil Language decline in the Malaysian context. It is noted that the Tamil language is considered as an authorized language in the country, nonetheless it has shown indications of failure in latest years compared to three other widely spoken languages. The most important reason for the decline is its squat socio-economic rank in comparison with other three languages since the Tamil language is tranquil connected by scarcity and shortage of societal and dogmatic impacts. Additional reasons include language faithfulness and language approach, language and identity, ethnicity and diglossia. A prescriptive, languagebased approach rules in the schools also causing the Tamil language progressively a 'classroom language' that has slight possibility of being used for daily interactions. The research maintains that it is needed to augment the utilization of the language amongst Tamil folk who are also Malaysian. In order to attain the end, it is vital to force people to utilize the language in the house, therefore filling the break amid the official and informal diversities of the language.
\end{abstract}

Keyword: English-Tamils; Malaysia; Social identity; Tamil language 